DOI: $10.5216 /$ cab.v13i4.15179

\title{
AVALIAÇÃO DA TOXICIDADE AGUDA DO EXTRATO HEXÂNICO DE FRUTOS DE Melia azedarach (MELIACEAE) EM CAMUNDONGOS
}

\author{
HÉlIO BERNARDES PIRES JÚNIOR ${ }^{1}$, LIGIA MIRANDA FERREIRA BORGES ${ }^{2}$, LORENA ALESSANDRA DiAS \\ DE SOUSA1, LuIZ CARLOS CUNHA ${ }^{2}$, RuY DE SOUZA LINO JÚNIOR ${ }^{2}$, DORCAS FERNANDES DOS ANJOS \\ MELO $^{3}$, MARCELO ELIAS PEREIRA ${ }^{4}$

\footnotetext{
${ }^{1}$ Pós-graduandos em Ciência Animal da Universidade Federal de Goiás, Goiânia, GO, Brasil.

${ }^{2}$ Professores Doutores da Universidade Federal de Goiás, Goiânia, GO, Brasil. - borges.ligia@ gmail.com

${ }^{3}$ Mestre em Farmácia pela Universidade Federal de Goiás, Goiânia, GO, Brasil

${ }^{4}$ Pós-graduando em Farmácia pela Universidade Federal de Goiás, Goiânia, GO, Brasil
}

Este trabalho foi desenvolvido visando avaliar a toxicidade aguda do extrato hexânico de frutos de Melia azedarach em camundongos. Foram compostos dois grupos tratados, sendo um para cada dose, $300 \mathrm{mg} / \mathrm{kg}$ e $2000 \mathrm{mg} / \mathrm{kg}$. Para cada grupo tratado foi utilizado um grupo controle não tratado. Todos os grupos foram compostos por seis animais, sendo três de cada sexo. Os animais foram avaliados aos 30 minutos, $1 \mathrm{~h}, 2 \mathrm{~h}, 4 \mathrm{~h}, 6 \mathrm{~h}$, $12 \mathrm{~h}$ e $24 \mathrm{~h}$ e a partir de então diariamente, até o $14^{\circ}$ dia após o tratamento, seguindo o screening hipocrático. A cada três dias, eles foram pesados e o consumo de ração foi medido. Foi avaliada a presença de alterações macroscópicas e microscópicas no coração, rins, pulmão, fígado, baço, intestinos e cérebro. Em ambas as doses nenhuma alteração em relação ao screening hipocrático foi observada. Somente os camundongos machos tratados com $2000 \mathrm{mg} / \mathrm{kg}$ apresentaram consumo de ração menor que o controle, mas, ainda assim, o ganho de peso foi semelhante entre os grupos. Não houve diferença significativa quanto ao peso dos órgãos entre os grupos, nem foram observadas alterações macroscópicas. Não foram encontradas alterações histopatológicas, com exceção de alterações pulmonares como hiperemia, hemorragia e edema nos grupos tratado e controle. Podese concluir que o extrato hexânico de frutos verdes de $M$. azedarach não apresenta toxicidade aguda sobre camundongos Swiss.

PALAVRAS-CHAVE: camundongos swiss; extrato hexânico de frutos verdes; histopatologia; Melia azedarach; toxicidade aguda.

\section{EVALUATION OF ACUTE TOXICOLOGICAL EFFECTS OF Melia azedarach (MELIACEAE) HEXANIC FRUIT EXTRACT ON SWISS MICE}

\section{ABSTRACT}

This study was developed aiming to evaluate the acute effects of Melia azedarach hexanic fruit extract on mice. Two treated groups, one for each dose, $300 \mathrm{mg} / \mathrm{kg}$ and $2000 \mathrm{mg} / \mathrm{kg}$, were prepared. For each treatment group, a non-treated control group was used. All groups were composed of six animals, three of each sex. The animals were evaluated at $30 \mathrm{~min} ., 1 \mathrm{~h}, 2 \mathrm{~h}, 4 \mathrm{~h}, 6 \mathrm{~h}, 12 \mathrm{~h}$ and $24 \mathrm{~h}$ and then daily, for 14 days after treatment, following the Hippocratic screening. At each three days weight gain and ration consumption were evaluated. Macroscopic and microscopic alterations were evaluated in the heart, kidneys, lungs, liver, spleen, intestine and brain. No alteration in the Hippocratic screening in both doses, during the 14-days interval, was observed. The mice treated with the $2000 \mathrm{mg} / \mathrm{kg}$ doses consumed fewer rations than the animals of the control group; however, weight gain was statistically similar. No statistic difference was observed between the weight of the organs, and they had no macroscopic alterations. No histopathologic alterations were found on the examined organs, for both doses, except for lung alterations such as hyperaemia, haemorrage and edema in both treated and 
control groups. Based on the results obtained, we fruits had no acute effects against Swiss mice. conclude that the hexanic extract of $M$. azedarach green

KEYWORDS: acute effects; hexanic extract of green fruits; histopathology; Melia azedarach; Swiss mice.

\section{INTRODUÇÃO}

O uso de plantas no controle de pragas agrícolas é uma das mais antigas práticas da humanidade (VENDRAMIM \& CASTIGLIONI, 2000), sendo relatadas mais de duas mil plantas com propriedades pesticidas conhecidas (ROEL, 2001). O uso popular e mesmo tradicional, entretanto, não é suficiente para validar as plantas medicinais como medicamentos eficazes e seguros (AGRA et al., 2007).

Evidências toxicológicas demonstram que toda substância é agente tóxico em potencial, dependendo apenas das condições de exposição, como dose administrada ou absorvida, tempo, frequência e via de administração (CASTRO, 1993). Assim, uma planta de uso terapêutico deve ter sua ação e nível tóxico previamente avaliados, a fim de se comprovar cientificamente os critérios de segurança (SIMÕES et al., 2004). Os testes toxicológicos são realizados para se ter dados sobre as condições em que os agentes químicos produzem efeitos tóxicos, qual a natureza desses efeitos e quais os níveis seguros de exposição (LOOMIS \& HAYES, 1996).

Melia azedarach L. (Meliaceae) é uma árvore originária da Índia, Pérsia e Sri Lanka (SILVA-JR, 1997), que se encontra distribuída em quase todos os países tropicais (BURKS, 1997). No Brasil, é conhecida popularmente como cinamomo, paraíso, santa-bárbara, jasmin-de-caiena, lilás-dachina, árvore-santa, loureiro-grego, chá-de-soldado, lilás-de-soldado, orgulho-da-índia, além de outras denominações. É uma árvore com altura superior a $10 \mathrm{~m}$, com folhas alternadas, longo-pecioladas, glabras, bipinadas, com folíolos ovais ou lanceolados e agudos. Apresenta flores pequenas, em grandes panículas eretas e multiflorais, cheirosas, lilases na cor e de anteras amarelas (BRAGA, 1976) (Fig. 1).

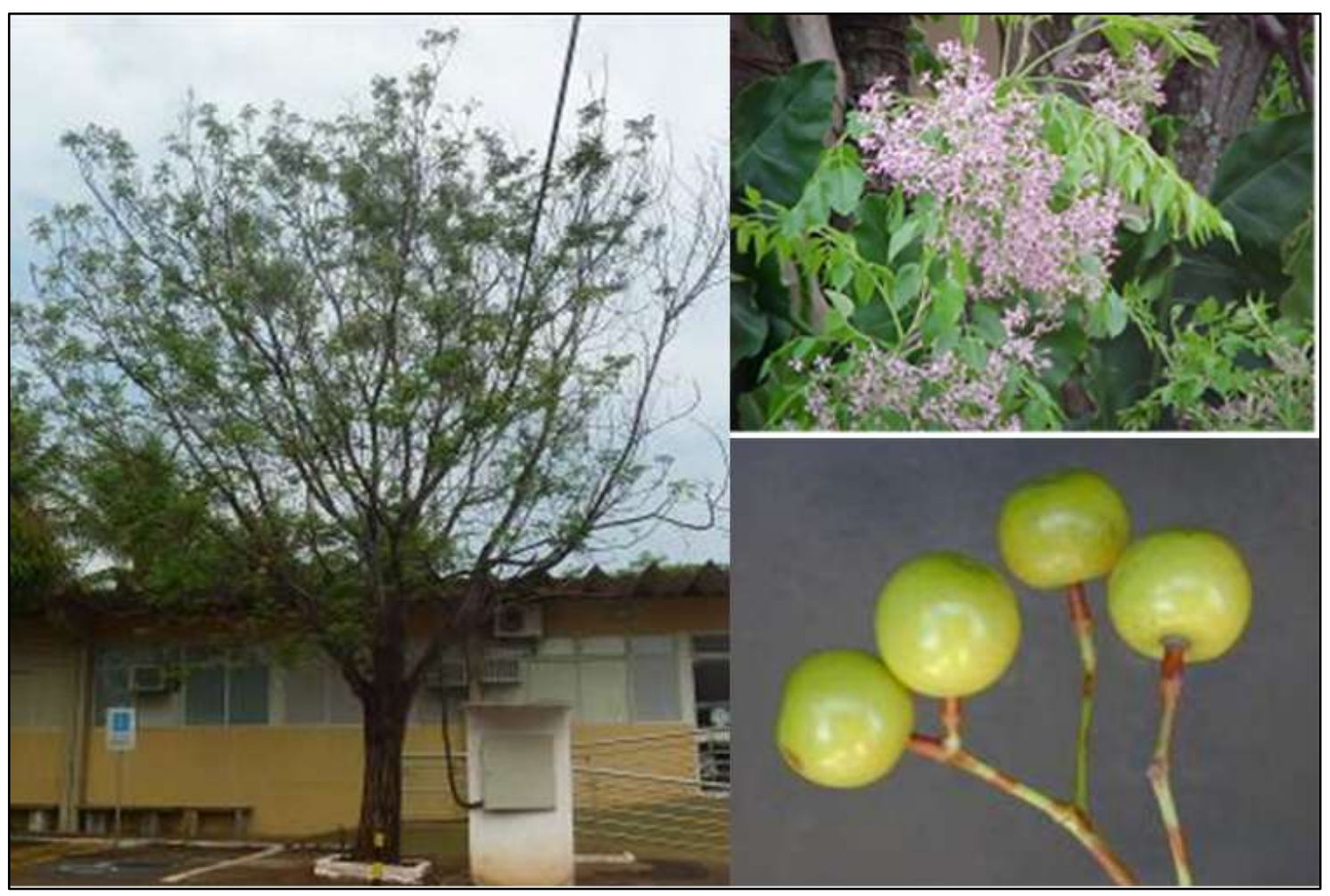

Figura 1 - Melia azedarach, Escola de Veterinária e Zootecnia da UFG - árvore, flores e frutos verdes (Fonte: arquivo pessoal) 
No Brasil, desde 1946, a utilização de extratos dessa planta já era recomendada para a proteção de culturas agrícolas contra o ataque de gafanhotos (LEPAGE et al., 1946). Diversas propriedades terapêuticas têm sido atribuídas a $M$. azedarach, como atividade antifúngica (CARPINELLA et al., 1999), inseticida (GAJMER et al., 2002), antiviral, antimalárica (KHAN et al., 2001) e anti-helmíntica (MCGRAW et al., 2000; JOSHI \& JOSHI, 2000), com grande destaque ao seu potencial como biopesticida. VALLADARES et al. (1999) observaram efeito repelente e inseticida dos extratos de frutos contra ovos e ninfas de Triatoma infestans. O extrato etanólico das sementes dessa planta foi eficaz contra larvas de Aedes aegypti (WANDSCHEER et al., 2004).

A atividade acaricida de $M$. azedarach também foi estudada sobre carrapatos, especialmente o Rhipicephalus microplus. Comparando in vitro extratos de frutos preparados com diferentes solventes - hexânico, alcoólico e clorofórmico BORGES et al. (2003) observaram maior eficácia do extrato hexânico sobre larvas e fêmeas ingurgitadas. Posteriormente, BORGES et al. (2005) e SOUSA et al. (2011) obtiveram resultados promissores do extrato hexânico dos frutos de $M$. azedarach no controle de $R$. microplus em bovinos infestados.

Intoxicações por $M$. azedarach têm sido observadas em animais domésticos e em humanos devido à ingestão de frutos e de folhas, sendo o fruto considerado mais tóxico que as folhas (KINGSBURY, 1964). MENDEZ et al. (2002) produziram intoxicação experimental em bovinos pela administração, em dose única oral, de folhas de M. azedarach, nas doses de 5 a $30 \mathrm{~g} / \mathrm{kg}$ de peso vivo. Os sinais clínicos observados foram depressão, atonia ruminal, fezes endurecidas com presença de sangue, incoordenação, tremores musculares, decúbito esternal, hipotermia e dores abdominais. Os sinais clínicos foram observados entre oito e 24 horas após a ingestão e o curso clínico durou entre duas e 72 horas. Três animais que receberam $30 \mathrm{~g} / \mathrm{kg}$ morreram. Cães que ingeriram acidentalmente os frutos apresentaram distúrbios gastrintestinais e no sistema nervoso central, culminando com a morte em 36 horas (SILVA-JR, 1997).

Estudos de intoxicação experimental também foram realizados em coelhos, administrando oralmente frutos triturados de $M$. azedarach, mas não se observou alteração clínica ou morte de animais nas doses de 20, 25 e $30 \mathrm{~g} / \mathrm{kg}$ (BEUTLER et al., 2008). SEFRIN et al. (2008) observaram que extratos aquosos de frutos verdes de $M$. azedarach nas concentrações de 2,5\%, 5,0\% e 10,0\% (p/v, $1 \mathrm{ml} / \mathrm{kg})(\approx 25,50$ e $100 \mathrm{mg} / \mathrm{kg})$ não causaram mortalidade, sinais clínicos ou alteração dos padrões bioquímicos, sobre ratos Wistar. Até o que se sabe, não há estudos avaliando a toxicidade aguda do extrato hexânico de frutos de M. azedarach.

Existe uma grande divergência com relação à toxicidade de $M$. azedarach. Segundo OELRICHS et al. (1983), a planta contém compostos limonoides conhecidos como meliatoxinas, que são tóxicos para os mamíferos; portanto, é necessário aprofundar as pesquisas relacionadas à sua toxicidade aos vertebrados antes de se recomendar sua utilização. Diante dos resultados promissores demonstrando os efeitos carrapaticidas obtidos com o extrato hexânico de frutos de M. azedarach (BORGES et al., $2003 \mathrm{e}$ 2005, SOUSA et al., 2008, 2011), da necessidade de se formular e comercializar produtos naturais seguros tanto ao homem como aos animais, desenvolveu-se este trabalho, com o objetivo foi avaliar a toxicidade pré-clínica aguda do extrato hexânico de frutos verdes de M. azedarach em camundongos Swiss.

\section{MATERIAL E MÉTODOS}

Frutos verdes de $M$. azedarach foram coletados no Campus II da Universidade Federal de Goiás - UFG, em Goiânia, GO (latitude 16² 41 'S; longitude $49^{\circ} 15^{\prime} \mathrm{W}$ ), (exsicata 27.611, Herbário da UFG) em fevereiro de 2008, sendo processados neste mesmo mês. Os frutos, após serem secos em estufa na temperatura de $40^{\circ} \mathrm{C}$, com circulação e renovação de ar, durante sete dias, foram triturados em moinhos de facas rotativas. Em seguida, foram submetidos à extração em Soxhlet, utilizando-se como solvente o hexano, que foi posteriormente evaporado em um rotaevaporador. $\mathrm{O}$ extrato foi armazenado em geladeira a $4^{\circ} \mathrm{C}$ até a sua administração aos animais.

O grupo experimental foi composto por camundongos Swiss (Mus musculus) pesando de 20 a $25 \mathrm{~g}$, não-isogênicos, provenientes do Biotério Central da UFG. Foram compostos dois grupos tratados, sendo um para cada dose, $300 \mathrm{mg} / \mathrm{kg}$ e $2000 \mathrm{mg} / \mathrm{kg}$. Para cada grupo tratado foi utilizado um grupo controle não tratado. Todos os grupos foram compostos por seis animais, sendo três de cada sexo.

No início do experimento, os animais foram aclimatados na Sala de Manutenção do Núcleo de Estudos e Pesquisas Tóxico-Farmacológicas da UFG (NEPET-UFG), por um período mínimo de cinco dias, sob condições padrão (temperatura de $25 \pm 3{ }^{\circ} \mathrm{C}$, umidade relativa do ar de 30 a $70 \%$, com controle do ciclo claro/escuro de $12 \mathrm{~h}$ ), para averiguação do comportamento, hábitos alimentares e fisiológicos. Os animais receberam ração (Purina Labina $\left.{ }^{\circledR}\right)$, água ad libitum e foram mantidos em gaiolas de polipropileno $(30 \times 20 \times 13 \mathrm{~cm})$, com três animais 
por gaiola. $\mathrm{O}$ experimento foi aprovado pelo Comitê de Ética em Pesquisa da UFG, registrado sob o número 107/2009.

Para o estudo da toxicidade aguda, foram adotadas as metodologias preconizadas pelo Guia para Testes de Químicos da OECD 423 (OECD, 2001). A dose inicial de $300 \mathrm{mg} / \mathrm{kg}$ foi selecionada com base no protocolo proposto pela OECD (OECD, 2001) para substâncias não testadas ou com histórico de toxicidade desconhecida. Como não foi observada morte nesta dose, testou-se a dose mais alta recomendada pelo mesmo protocolo, $2000 \mathrm{mg} / \mathrm{kg}$.

Para administração do extrato, todos os animais foram privados de alimento por oito horas e pesados para ajuste do volume a ser administrado. $\mathrm{O}$ extrato foi diluído em DMSO 5\% em solução salina e administrado aos animais por via oral (gavagem), através de uma cânula apropriada. Administrou-se o veículo (DMSO 5\% em solução salina) ao grupo controle pela mesma via. Foi administrado o volume máximo de $1 \mathrm{~mL} / 100 \mathrm{~g}$ de peso vivo.

Os animais foram avaliados aos 30 minutos, $1 \mathrm{~h}, 2 \mathrm{~h}, 4 \mathrm{~h}, 6 \mathrm{~h}, 12 \mathrm{~h}$ e $24 \mathrm{~h}$ e, a partir de então, diariamente, até o $14^{\circ}$ dia após o tratamento. Foram avaliados os seguintes sinais seguindo o screening hipocrático: atividade geral, frênito vocal, irritabilidade, resposta ao toque, resposta ao aperto de cauda, contorção, posição do trem posterior, reflexo de endireitamento, tônus do corpo, força para agarrar, ataxia, reflexo auricular, reflexo corneal, tremores, convulsões, anestesia, lacrimação, ptose, micção, defecação, piloereção, hipotermia, respiração, cianose, hiperemia e morte. Os sinais avaliados na observação comportamental e exame clínico sistemático dos animais foram registrados em protocolo impresso com a lista de sinais a serem investigados (MALONE \& ROBICHAUD, 1962; MALONE, 1977).

Os animais foram pesados a cada três dias, durante os 14 dias de tratamento, para a avaliação do ganho de peso. Para determinação do consumo de ração, esta era pesada no momento de ser disponibilizada aos animais e posteriormente no dia de limpeza das gaiolas.

Ao final dos experimentos, todos os animais foram anestesiados com solução xilazina-cetamina $0,2 \mathrm{~mL} / 100 \mathrm{~g}$, pela via intraperitoneal $(8,75 \mathrm{~mL}$ de cetamina $(100 \mathrm{mg} / \mathrm{mL})$ e $1,25 \mathrm{~mL}$ de xilazina $(100$ $\mathrm{mg} / \mathrm{mL})$ ), via i.p., conforme protocolo da Cornell University/Cornell Center for Animal Resources and Education (FLECKNELL, 1996, KOHN et al., 1997) e eutanasiados por deslocamento cervical de acordo com "os princípios éticos de experimentação animal", proposta pela Sociedade Brasileira de Ciência em Animais de Laboratório (SBCAL/COBEA) e atendendo à lei 11.794 de 11 de outubro de 2008 (BRASIL, 2008) e à Resolução ${ }^{\circ}$ 01 do Conselho Nacional de Saúde de 13 de junho de 1988 (BRASIL, 1988). As cavidades abdominal e torácica foram abertas e todas as alterações macroscópicas foram registradas. Em seguida, coração, rins, pulmão, fígado, baço, intestino (delgado e grosso) e cérebro foram coletados e pesados. O peso relativo dos órgãos foi calculado dividindo-se o peso do órgão pelo peso do animal e multiplicando-se por 100.

Para a análise histopatológica, fragmentos de todos os órgãos citados acima foram fixados em formaldeído a $10 \%$, processados para inclusão em parafina e corados pela técnica de hematoxilinaeosina (HE). Foram analisados os seguintes processos patológicos: alterações celulares, intersticiais, vasculares, inflamatórias e distúrbios no crescimento e diferenciação celulares (JUNQUEIRA \& JUNQUEIRA, 1983).

Para verificar diferenças significativas entre os grupos estudados, foi aplicado o teste de análise de variância (ANOVA). As médias foram comparadas através dos testes de $t$ de Student e de Tukey com nível de significância de $p<0,05$.

\section{RESULTADOS E DISCUSSÃO}

Não foi observada morte dos animais, na avaliação aguda do extrato hexânico de frutos verdes de $M$. azedarach sobre camundongos Swiss na dose de $300 \mathrm{mg} / \mathrm{kg}$ e $2000 \mathrm{mg} / \mathrm{kg}$, no período de 14 dias. Da mesma forma, nenhuma alteração em relação ao screening hipocrático foi observada, sendo o comportamento do grupo tratado semelhante ao do grupo controle em ambas as doses.

Não houve diferença de consumo de ração no grupo dos camundongos fêmea em ambas as doses e no grupo macho tratado com $300 \mathrm{mg} / \mathrm{kg}$. Somente os camundongos machos tratados com 2000 $\mathrm{mg} / \mathrm{kg}$ apresentaram consumo de ração menor que o controle. Ainda assim, o ganho de peso obtido com ambas as doses avaliadas, tanto em machos como em fêmeas, foi semelhante com o grupo controle, evidenciando a não influência do extrato nesse parâmetro (Tabela 1).

Não se observou alteração macroscópica e também não houve diferença significativa quanto ao peso dos pulmões, fígado, rins, coração, cérebro, baço e intestinos entre os grupos controle e tratado em ambas as doses, tanto para machos quanto para fêmeas, demonstrando que nenhum dos órgãos avaliados foi alterado pelo tratamento com o extrato (Tabela 2).

Não foram encontradas alterações histopatológicas no baço, coração, cérebro, fígado, intestinos e rins de camundongos machos e fêmeas 
tratados com as doses de $300 \mathrm{mg} / \mathrm{kg}$ e $2000 \mathrm{mg} / \mathrm{kg}$. Foram observadas alterações no pulmões, no entanto, elas ocorreram da mesma forma em ambos os grupos (tratados e controles). As alterações observadas foram hiperemia (seis animais), hemorragia (um animal) e edema (um animal) no grupo tratado com
$300 \mathrm{mg} / \mathrm{kg}$, assim como no seu controle (quatro animais com hiperemia, dois com hemorragia e dois com edema). No grupo tratado com $2000 \mathrm{mg} / \mathrm{kg}$, seis animais tiveram hiperemia e no seu controle seis tiveram hiperemia e dois hemorragia.

Tabela 1. Média \pm desvio padrão dos consumos de ração e de ganho de peso de camundongos Swiss, machos e fêmeas, tratados com as doses de 300 e $2000 \mathrm{mg} / \mathrm{kg}$ de extrato hexânico de frutos verdes de Melia azedarach, e animais controle

\begin{tabular}{lccccc}
\hline \multirow{2}{*}{ Tratamento } & \multicolumn{2}{c}{ Fêmeas } & & \multicolumn{2}{c}{ Machos } \\
\cline { 2 - 3 } \cline { 5 - 6 } & $\begin{array}{c}\text { Consumo de } \\
\text { ração }(\mathrm{g})\end{array}$ & $\begin{array}{c}\text { Ganho de peso } \\
(\mathrm{g})\end{array}$ & & $\begin{array}{c}\text { Consumo de } \\
\text { ração }(\mathrm{g})\end{array}$ & $\begin{array}{c}\text { Ganho de peso } \\
(\mathrm{g})\end{array}$ \\
\hline $300 \mathrm{mg} / \mathrm{kg}$ & $18,28 \pm 3,40 \mathrm{a}$ & $4,66 \pm 1,52 \mathrm{a}$ & & $21,21 \pm 2,15 \mathrm{a}$ & $6,30 \pm 0,57 \mathrm{a}$ \\
Controle & $16,5 \pm 1,55 \mathrm{a}$ & $5,00 \pm 1,73 \mathrm{a}$ & & $19,92 \pm 0,99 \mathrm{a}$ & $4,66 \pm 1,15 \mathrm{a}$ \\
& & & & & \\
$2000 \mathrm{mg} / \mathrm{kg}$ & $15,38 \pm 1,40 \mathrm{a}$ & $4,66 \pm 0,57 \mathrm{a}$ & & $16,57 \pm 1,22 \mathrm{~b}$ & $4,66 \pm 4,5 \mathrm{a}$ \\
Controle & $15,14 \pm 1,29 \mathrm{a}$ & $4,00 \pm 1,00 \mathrm{a}$ & & $20,14 \pm 0,66 \mathrm{a}$ & $8,30 \pm 3,78 \mathrm{a}$ \\
\hline
\end{tabular}

Em uma mesma categoria e tratamento, as médias seguidas de letras desiguais, diferem entre si estatisticamente pelo teste de $T$ de Student $(\mathrm{p}<0,05)$, em relação ao grupo tratado e controle.

Tabela 2. Peso relativo dos órgãos (\%) de camundongos machos e fêmeas dos grupos controle e tratado com extrato hexânico de frutos verdes de Melia azedarach, na dose de 300 e $2000 \mathrm{mg} / \mathrm{kg}$

\begin{tabular}{lcccccccc}
\hline & \multicolumn{6}{c}{ Machos } \\
\cline { 2 - 9 } Órgão & Controle & $300 \mathrm{mg} / \mathrm{kg}$ & Controle & $2000 \mathrm{mg} / \mathrm{kg}$ & Controle & $300 \mathrm{mg} / \mathrm{kg}$ & Controle & $2000 \mathrm{mg} / \mathrm{kg}$ \\
\hline Pulmões & $0,54 \pm 0,05$ & $0,53 \pm 0,07$ & $0,67 \pm 0,17$ & $0,71 \pm 0,12$ & $0,78 \pm 0,37$ & $0,62 \pm 0,07$ & $0,85 \pm 0,1$ & $0,98 \pm 0,03$ \\
Fígado & $4,66 \pm 0,51$ & $5,30 \pm 0,65$ & $5,90 \pm 1,09$ & $6,20 \pm 0,92$ & $5,83 \pm 2,14$ & $5,9 \pm 0,36$ & $5,50 \pm 0,70$ & $6,02 \pm 0,58$ \\
Coração & $0,51 \pm 0,06$ & $0,46 \pm 0,16$ & $0,44 \pm 0,04$ & $0,52 \pm 0,02$ & $0,56 \pm 0,10$ & $0,47 \pm 0,02$ & $0,40 \pm 0,06$ & $0,39 \pm 0,04$ \\
Rins & $1,26 \pm 0,07$ & $1,44 \pm 0,29$ & $1,46 \pm 0,08$ & $1,72 \pm 0,38$ & $1,21 \pm 0,15$ & $1,24 \pm 0,09$ & $1,11 \pm 0,12$ & $1,16 \pm 0,18$ \\
Cérebro & $0,93 \pm 0,04$ & $1,01 \pm 0,13$ & $0,92 \pm 0,15$ & $1,15 \pm 0,21$ & $1,16 \pm 0,07$ & $1,16 \pm 0,07$ & $1,24 \pm 0,07$ & $1,35 \pm 0,02$ \\
Baço & $0,29 \pm 0,05$ & $0,29 \pm 0,15$ & $0,29 \pm 0,02$ & $0,31 \pm 0,03$ & $0,71 \pm 0,73$ & $0,34 \pm 0,01$ & $0,35 \pm 0,02$ & $0,35 \pm 0,05$ \\
\hline
\end{tabular}

Não houve diferença significativa entre os grupos controle e tratado - teste de Tukey $(\mathrm{p}<0,05)$.

O extrato hexânico de frutos verdes de $M$. azedarach não causou a morte de animais tampouco alterações clínicas no screening toxicológico, durante o período de observação, nos camundongos tratados com as doses de $300 \mathrm{mg} / \mathrm{kg}$ e $2000 \mathrm{mg} / \mathrm{kg}$. Esses dados caracterizam o extrato como de baixa toxicidade aguda, pois esta é observada quando ocorrem efeitos adversos após a administração oral de uma simples dose, em curta duração (OECD, 2001).

$\mathrm{O}$ extrato de $M$. azedarach enquadra-se na Classe 5, pois a estimativa da DL 50 foi superior a $2000 \mathrm{mg} / \mathrm{kg}$, sendo considerado de baixa toxicidade de acordo com o método de classes preconizado pela OECD 423 (OECD, 2001). A dose seguinte a ser testada seria a de $5000 \mathrm{mg} / \mathrm{kg}$; no entanto, o estudo dessa dosagem somente é recomendado em casos excepcionais que justifiquem a sua necessidade.
Como a dose tóxica de $M$. azedarach sobre carrapatos, nos quais testes com extratos hexânicos têm sido avaliados, é baixa $(0,25 \% \approx 0,25 \mathrm{~g} / \mathrm{kg})$ (BORGES et al., 2003, 2005; SOUSA et al., 2008, 2011), estudos com essa dose não são recomendados, tanto por questões de bioética animal quanto por questões técnicas. Afinal, alterações em doses muito elevadas poderiam ocorrer por descompensação do organismo avaliado e não necessariamente por uma ação tóxica específica.

A toxicidade sistêmica de determinada substância pode se manifestar, também, por meio da redução nos consumos de água e ração, alteração comportamental, apatia, má condição de pelagem e alteração da massa relativa dos órgãos (MELO, 2001; GONZÁLEZ \& SILVA, 2003). O peso corporal é um dos parâmetros mais empregados em avaliações toxicológicas para indicar o aparecimento, 
muitas vezes precoce, de efeitos tóxicos de uma determinada substância no organismo animal. A ausência de alterações nos parâmetros fisiológicos avaliados enfatiza a baixa toxicidade do extrato de M. azedarach aqui avaliado. $\mathrm{O}$ mesmo pode ser dito a partir da análise microscópica dos órgãos, que não revelou alterações no fígado, rins e intestinos, órgãos importantes no metabolismo e excreção de xenobióticos (HAYES, 2001).

Embora a toxicidade e os constituintes tóxicos de $M$. azedarach já tenham sido bem determinados (OELRICHS et al., 1983, 1985; HUANG et al., 1995), no presente estudo não foram observados sintomas de toxicidade. Resultados semelhantes foram obtidos por SEFRIN et al. (2008), que observaram que extratos aquosos de frutos verdes de $M$. azedarach não causaram mortalidade nem alterações clínicas nas concentrações de até 100 $\mathrm{mg} / \mathrm{kg}$ sobre ratos Wistar. Resultados semelhantes também foram obtidos por COSTA-SILVA et al. (2008) que, avaliando a toxicidade aguda do extrato hexânico de frutos de Carapa guianensis, planta também da família Meliaceae, demonstraram que as doses de $750 \mathrm{mg} / \mathrm{kg}$ e $1.500 \mathrm{mg} / \mathrm{kg}$ não produziram sinais de toxicidade e/ou mortalidade.

A baixa toxicidade de uma planta pode ser inerente à sua composição química, mas pode também ser explicada por influências biogeográficas, pela parte da planta utilizada para o preparo dos extratos, pelo solvente utilizado, entre outros (HURST, 1942; OELRICHS et al., 1985), bem como pela variedade da planta (BEUTLER et al., 2008). Sabe-se que, em $M$. azedarach, a presença de diferentes compostos já foi identificada em frutos de plantas provenientes de diferentes regiões do mundo (MORGAN \& THORNTON, 1973; ARIAS \& HIRSCHMAN, 1988; CABRAL et al., 1996). Vale enfatizar que o extrato utilizado no desenvolvimento do presente trabalho foi preparado a partir de exemplares de $M$. azedarach que apresentaram alta eficácia sobre o carrapato $R$. microplus (BORGES et al., 2003).

\section{CONCLUSÃO}

Pode-se concluir, portanto, que o extrato hexânico de frutos verdes de $M$. azedarach na dose de até $2000 \mathrm{mg} / \mathrm{kg}$ não apresenta toxicidade aguda sobre camundongos Swiss. Ainda assim, ensaios adicionais de toxicidade sub-aguda e crônica, efeitos sobre organismos específicos e sobre o meio ambiente, a fim de definir esta planta como de baixo risco ao ambiente, animais domésticos e ao homem, são necessários.

\section{AGRADECIMENTOS}

Os autores expressam agradecimento à Fundação de Amparo à Pesquisa do Estado de Goiás - FAPEG pelo auxílio financeiro para a execução deste trabalho.

\section{REFERÊNCIAS}

AGRA, M. F.; FREITAS, P. F.; BARBOSA-FILHO, J. M. Synopsis of the plants known as medicinal and poisonous in Northeast of Brazil. Revista Brasileira de Farmacognosia, v.1, p.114-140, 2007.

ARIAS, A. R.; HIRSHMAN, C. S. The effects of Melia azedarach on Triatoma infestans bugs. Fitoterapia, v.59, n.2, p.148-149, 1988.

BEUTLER, H. P.; MAIER, E. M.; PETERS, G. B.; ROSSATO, C. K. Intoxicação experimental com frutos de Melia azedarach em coelhos. Anais $35^{\circ}$ do Conbravet, Gramado, RS (resumo), 2008. http://www.sovergs.com.br/conbravet2008/anais/cd/.

BORGES, L. M. F.; FERRI, P. H.; SILVA, W. J.; SILVA, W. C. In vitro efficacy of extracts of Melia azedarach against the tick Boophilus microplus. Medical and Veterinary Entomology, v.17, p.228-231, 2003.

BORGES, L. M. F., FERRI, P. H., SILVA, W. C., SILVA, W. J., MELO, L. S., SOUZA, L. A. D., SOARES, S. F., FARIA, K. A., GOMES, N. A., MORI, A. S., SILVA, N.F. Ação do extrato hexânico de frutos maduros de Melia azedarach (Meliaceae) sobre Boophilus microplus (Acari: Ixodidae) em bezerros infestados artificialmente. Revista de Patologia Tropical, v. 34, p.53-59, 2005.

BRAGA, R. Plantas do Nordeste, especialmente do Ceará. 3.ed.: ESAM, Mossoró, 1976. p.191-192

BRASIL. Casa civil. Subchefia para Assuntos Jurídicos. Lei 11.794 de 8 de outubro de 2008. Regulamenta o inciso VII do $\S 10$ do art. 225 da Constituição Federal, estabelecendo procedimentos para o uso científico de animais; revoga a Lei no 6.638, de 8 de maio de 1979; e dá outras providências. Diário Oficial [da] República Federativa do Brasil, Brasília, DF, 09 de outubro de 2008.

BRASIL. Ministério da Saúde. Resolução no 01, de 13 de junho de 1988 - Dispõe sobre normas de pesquisa em saúde. Brasília: Conselho Nacional de Saúde, 1988.

BURKS, K. C. Melia azedarach. Fact sheet prepared by the Bureau of Aquatic Plant Mangement. Tallahasse: Department of Environment Protection, State of Florida, Tallahassee, FL, 1997.

CABRAL, M. M. O.; GARCIA, E. S.; REMBOLD, H.; SIMONE, S. G.; KELECOM, A. Anti-moulting activity in Brazilian Melia azedarach. Memórias do Instituto Oswaldo Cruz v.91, p.117-118, 1986. 
CARPINELLA, M. C.; HERRERO, G. G.; ALONSO, R. A.; PALACIOS, S. M. Antifungal activity of Melia azedarach fruit extract. Fitoterapia, v.70, p.296-298, 1999.

CASTRO, J. A. Toxicologia básica: mecanismos de toxicidade y sus applicaciones. Acta Bioquímica Clínica Latinoamericana, v.2, p.197-206, 1993.

COSTA-SILVA, J. H.; LIMA, C. R.; SILVA, E. J. R.; ARAUJO, A. V.; FRAGA, M. C. C. A.; RIBEIRO, E.; RIBEIRO, A.; ARRUDA, A. C.; LAFAYETTE, S. S. L.; WANDERLEY, A. G. Acute and subacute toxicity of the Carapa guianensis Aublet (Meliaceae) seed oil. Journal of Ethnopharmacology, v.116, p.495-500, 2008.

FLECKNELL, P. Laboratory animal anesthesia., $2^{\text {nd }}$ ed. Academic Press, New York, 1996. 274p.

GAJMER, T.; SINGH, R.; SAINI R. K., KALIDHAR, S. B. Effect of methanolic extracts of neem (Azadirachta indica A. Juss) and bakain (Melia azedarach) seeds on oviposition and egg hatching of Earias vittella (Fab) (Lep., Noctuidae). Journal of Applied Entomology, v.126, p.238-243, 2002.

GONZALEZ, F. H. D.; SILVA, S. C. Introdução à Bioquímica Clínica Animal. Gráfica de Universidade Federal do Rio Grande do Sul, Porto Alegre. 2003. 198p.

HAYES, A. W. Principles and methods of toxicology. CRC Press, New York, 2001. 1887p.

HUANG, R. C. H.; OKAMURA H.; IWAGAWA T.; TADERA K. Azedarachin C, a limonoid antifeedant from Melia azedarach. Phytochemistry v.38, p.593-594, 1995.

HURST, E. Poisonous plants of New South Wales Plants Committee, New South Wales., 1942. 342p.

JOSHI, A. R., JOSHI K. Indigenous knowledge and uses on medicinal plants by local communities of the kali gandaki watershed area, Nepal. Journal of Ethnopharmacology, v.73, p.175-183, 2000.

JUNQUEIRA, L. C. U., JUNQUEIRA, L. M. M. S. Técnicas básicas de citologia e histologia. Guanabara Koogan, Rio de Janeiro, 1983. 123p.

KHAN, M. R., KIHARA, M.; OMOLOSO, A. D. Antimicrobial activity of Horsfieldia helwiigi and Melia azedarach. Fitoterapia, v.72, p.423-427, 2001.

KOHN, D. F.; WIXSON S.K.; WHITE W.J.; BENSON G.J. Anesthesia and analgesia in laboratory animals. New York, Academic Press.1997. 426p.

KINGSBURY, J. M. 1964. Poisonous Plants of the United States and Canada. Prentice-Hall, Englewood Cliffs, NJ, 1964. p. 206-208.

LEPAGE, H.S.; GIANOTTI, O.; ORLAND, A. Proteção das culturas contra os gafanhotos por meio de extratos de Melia azedarach. O Biológico, v.12, p.265-271, 1946.

LOOMIS, M. D.; HAYES A.W. Loomis essentials of toxicology. 4ed. Academic Press, San Diego, 1996. 282p.

MALONE, M. H. Pharmacological approaches to natural product, screening and evaluation. In: Wagner H. \& Wolf P. (Eds), Natural Products and Plant Drugs with Pharmacological, Biological or Therapeutical Activity., Springer-Verlag, Berlin, 1977. p.23-53.

MALONE, M. H.; ROBICHAUD. R. C. A hippocratic screening for pure or drug materials. Lloydia, v.25, p.2353,1962 .

MCGRAW, L. J.; JÄGER, A. K.; VAN STADEN, J. Antibacterial, anthelmintic and antiamoebic activity in South African medicinal plants. Journal of Ethnopharmacology, v. 72, p.247-263, 2000.

MELO, F. B. Estudo dos efeitos de Lantana camara (Verbenaceae) sobre a fertilidade e reprodução de ratos. Dissertação de Mestrado em Ciências Veterinárias, Escola de Veterinária, Universidade Federal do Rio Grande do Sul, Porto Alegre, 2001. 120p. Disponível em http://www.ufrgs.br/actavet/29-2/dissertacao2.pdf, Acesso em 10 de novembro de 2012.

MÉNDEZ, M. C.; ARAGÃO, M.; ELIAS, F.; RIETCORREA, F.; GIMENO, E. J. Experimental intoxication by leaves of Melia azedarach (Meliaceae) in cattle. Pesquisa Veterinária Brasileira, v.22, p.19-24, 2002.

MORGAN, E. D.; THORNTON, M. D. Azadirachtin in the fruit of Melia azedarach. Phytochemistry, v.12, p.391-392, 1973 .

OECD- Organization for Economic Co-operation and Development. Guideline 423: Acute Oral Toxicity-Acute Toxic Class Method. OECD, Paris, 2001. 14p.

OELRICHS, P. B.; HILL, M. W.; VALLEY, P. J.; MACLEOD, J.K.; MOLINSKI, T. F. Toxicity tetranortriterpenes of the fruit of Melia azedarach. Phytochemistry, v.22, p.531-534, 1983.

OELRICHS, P. B.; HILL, M. W.; VALLEY, P. J.; MACLEOD, J. K.; MOLINSKI, T. F. The chemistry and pathology of meliatoxins A and B constituents from the fruit of Melia azedarach L. var. australasica. In: Seawright A.A., Hegarty M.P. \& James L.F. (Eds) Plant Toxicology. Queensland Poisonous Committee, Yeerongpilly, 1985. p. 387-394.

ROEL, A. R. Utilização de plantas com propriedades inseticidas: uma contribuição para o desenvolvimento rural sustentável. Interações: Revista Internacional de Desenvolvimento Local, v. 1, p.43-50, 2001.

SEFRIN, R. C. A. S.; COSTA, E. C.; BORGES, L.; BORGES V. C.; NASCIMENTO P. C.; DEQUECH, S. T. B.; SAUSEN, C. D. Extratos aquosos de frutos verdes de Melia azedarach L. var. azedarach: Investigação da presença de cianeto e avaliação toxicológica. Biotemas, v. 21, p.143-147, 2008.

SILVA-JR, A. A. Plantas Medicinais. Florianópolis: EPAGRI, CD-ROM., 1997.

SIMÕES, C. M. O.; SCHENKEL, E. P.; GOSMANN, G.; MELLO, J. G. C.; MENTZ, L. A.; PETROVICK P. Farmacognosia: da Planta ao Medicamento. 5ed., Editora da Universidade Federal do Rio Grande do Sul, 
Porto Alegre, 2004. 1096p.

SOUZA, L. A. D., SOARES, S. F., PIRES, H. B., FERRI, P. H., BORGES, L. M. F. Avaliação da eficácia de extratos oleosos de frutos verdes e maduros de cinamomo (Melia azedarach) sobre Rhipicephalus (Boophilus) microplus (Acari: Ixodidae). Revista Brasileira de Parasitologia Veterinária, v. 17, p. 36-40, 2008.

SOUSA, L. A. D.; PIRES, H. B.; SOARES, S. F.; FERRI, P. H.; RIBAS, P.; LIMA, E. M.; FURLONG, J.; BITTENCOURT, V. R. E. P.; PERINOTTO, W. M. S.; BORGES, L. M. F. Potential synergistic effect of Melia azedarach fruit extract and Beauveria bassiana in the control of Rhipicephalus (Boophilus) microplus (Acari:
Ixodidae) in cattle infestations. Veterinary Parasitology, v. 175, p.320-324, 2011.

VENDRAMIM, J. D.; CASTIGLIONI, E. Aleloquímicos, resistência de plantas e plantas inseticidas. In: Bases e Técnicas do Manejo de Insetos, Santa Maria, Ed. Pallotti, 2000. p.113-128.

WANDSCHEER, C. B.; DUQUE, J. E.; SILVA, M. A. N.; FUKUYAMA, Y.; WOHLKE, J. L.; ADELMANN, J.; FONTANA, J. D. Larvicidal action of ethanolic extracts from fruit endocarps of Melia azedarach and Azadirachta indica against the dengue mosquito Aedes aegypti. Toxicon, v.44, p.829-835, 2004.

Protocolado em: 01 ago. 2011. Aceito em 12 nov. 2012 